\title{
Analysis of Pragmatic Functions of "Smile" Emoji in Chinese WeChat Communication Between People of Different Ages
}

\author{
SUN Wantong \\ University of Shanghai for Science and Technology, Shanghai, China
}

\begin{abstract}
With the rapid development of social media, emojis have gradually become an indispensable communication tool in computer-mediated communication (CMC). In recent years, researchers have found that emojis not only have semantic and syntax functions (e.g., punctuation), but also perform pragmatic functions. Therefore, this thesis is to investigate the differences in pragmatic functions of "smile" emoji between people of different ages. And this paper is a small-scale quantitative research based on the eight pragmatic functions of emoticons proposed by Yus (2014). To find out similarities and differences of "smile" emoji between people of different ages, this paper compared the use frequency and pragmatic functions of "smile" emoji in two WeChat groups which are from youth and middle-aged people and did statistical analysis by Statistic Package for Social Science (SPSS). According to similarities and differences in frequency and pragmatic functions, "smile" emoji can be divided into four categories, which are: (1) similar frequency but different functions; (2) different frequency but similar function, (3) emojis exist only in one group; and (4) similar in both use frequency and function. So, the results suggest that there is a difference between people of different ages using "smile" emoji in WeChat communication. Thus, this study will provide insights into how to use emojis in WeChat when people at different ages communicate with each other can make a successful conversation.
\end{abstract}

Keywords: smile emoji, pragmatic functions, frequency, WeChat communication

\section{Introduction}

WeChat, a free multi-modal online application program in China, was launched by Tencent in January, 2011. Due to its low cost and convenient communicative function, in 2018, WeChat has become the most used social media in China, through which users can text messages, send voice messages, share videos, and make video or voice call with anyone who exists in users' friends list. Typed WeChat communication systems are referred to as quasi-synchronous because utterance typed by user are revised and repeated consideration, which is different from face-to-face communication and video call which are fully synchronous and different from letter which is fully asynchronous (Crystal, 2001).

People found that absolutely text communication sometimes could not accurately convey the meaning of users, so emoji was added in WeChat communication. Researchers found that users interpret emoji in different ways and use it beyond its surface meaning. Through observing linguistic data and reading previous studies,

SUN Wantong, Master degree, College for Foreign Language, University of Shanghai for Science and Technology, Shanghai, China. 
researchers found the smile related emoji is used the most frequently and is used differently in different groups of people (Provine, Spender \& Mandell, 2007).

This study provides both quantitative research and qualitative research which examines whether there are differences between people of different ages in the using of "smile" emoji in Chinese WeChat communication, including the use frequency of each emoji, and the pragmatic functions of each emojito investigate how different people understand the same emoji in different ways and aims to use emoji to achieve successful communication between people of different ages.

\section{Literature Review}

Emoji, a Japanese word for ideograms or smileys used in Japanese electronic messages, means "picture letter". Due to the increasing popularity of using emoji in digital communicative platforms, scholars at home and abroad have found that emojis play an extremely important role in online communication, so research in pragmatics up to date (Ge \& Herring, 2018).

Rezabek and Cochenour (1998), examining the frequency of emoticons from emails, found that the most frequent use emoticons are traditional smiley face and smiley face without nose. A similar research conducted by Provine, Spender and Mandell (2007) had analogical result that the most frequent use emoticons in website are smile and laugh. Additionally, Rezabek and Cochenour (1998) pointed out there are many influence factors, such as gender, age, and personal performance, but they did not follow up their research on these factors. Based on their research results, some other scholars carried on research about gender, location, and cultural effects. For example, Witmer and Katzman (1997) and Tossell, Kortum, Shepard, and Barg-Walkow (2012) found that women use twice than men in computer-mediated communication (CMC).

Besides it initially designed as indicator of affective states, researchers observed emoji, as a new form of human language, have pragmatic functions. One of the most important functions is non-seriously interpreted messages (Glenn, 2003; Holt, 2013; Dresner \& Herring, 2010). Ikeda and Bysouth (2013) pointed out emoticons used solo in online conversation serve functions as turning-taking and back-channel signals. Different emojis have different functions in different communication situations. While Kavanagh (2010) made classification of pragmatic functions of emojis in details into nine categories: modest devices, hedges, humors, to express emotion, to soften request, to show politeness, rapport management, emphatic use, and lexical use. Darics (2012) indicated five functions of emoji in her research: emotional display; discursive function; linguistic function; semantic function; and interactional function.

Form the literature review above, we can conclude that there are many researches about the location, frequency and pragmatic functions of emoji; however, those researches mainly focused only on a single aspect and research materials mostly ignored the specific features of the most frequent use emoji compared to other emojis. Moreover, research was conducted to examine the differences of use emoji between people in different gender, but differences between people of different ages were unnoticed. So, this paper aims to investigate different functions in using "smile" emoji between people of different ages.

\section{Method}

In this section, the author will introduce the theoretical framework of the study based on eight pragmatic functions of emoticons proposed by Yus (2014). 
Table 1

Eight Pragmatic Functions Proposed by Yus

\begin{tabular}{|c|c|}
\hline Pragmatic functions & Explanation \\
\hline $\begin{array}{l}\text { (1) To signal the propositional attitude that underlines the } \\
\text { utterance and which would be difficult to identify without the } \\
\text { aid of the emoticon. }\end{array}$ & $\begin{array}{l}\text { Facial expression, body language or intonation would not be } \\
\text { displayed in communication on keyboard. Therefore, emoticons } \\
\text { play the attitude signal role. }\end{array}$ \\
\hline $\begin{array}{l}\text { (2) To communicate a higher intensity of a propositional } \\
\text { attitude which has already been coded verbally }\end{array}$ & $\begin{array}{l}\text { Message senders have already shown their attitude through } \\
\text { message, and then they add relevant emoticons to strength their } \\
\text { attitude. }\end{array}$ \\
\hline (3) To strengthen $\backslash$ mitigate the illocutionary force of a speech act & $\begin{array}{l}\text { This pragmatic function is used to enhance or soften the } \\
\text { illocutionary force of speech acts. }\end{array}$ \\
\hline (4) To contradict the explicit content of the utterance: joking & $\begin{array}{l}\text { Message sender indicated the receiver to interpret the message } \\
\text { in a non-serious way to express a sense of humorous through } \\
\text { emoticons. }\end{array}$ \\
\hline (5) To contradict the explicit content of the utterance: irony & $\begin{array}{l}\text { The message sender usually expresses the satiric attitude and } \\
\text { hopes the receivers aware of this attitude. }\end{array}$ \\
\hline $\begin{array}{l}\text { (6) To add a feeling of emotion towards the propositional } \\
\text { content of the utterance }\end{array}$ & $\begin{array}{l}\text { This function is used to indicate the senders' feeling towards the } \\
\text { utterance. }\end{array}$ \\
\hline (7) To add a feeling of emotion towards the communicative act & $\begin{array}{l}\text { This function is used to indicate the senders' feeling at the } \\
\text { moment of editing information }\end{array}$ \\
\hline $\begin{array}{l}\text { (8) To communicate the intensity of a feeling of emotion that } \\
\text { has been coded verbally }\end{array}$ & $\begin{array}{l}\text { Emoticons can be used for enhancing the intensity of a feeling } \\
\text { or emotion which has already been coded verbally in the } \\
\text { message. }\end{array}$ \\
\hline
\end{tabular}

Yus (2014) claimed the boundary between the term of emotion and the term of attitude. So, in the progress of analysis, Function (6) is combined with Function (1) and Function (8) is combined with Function (2). Because of the complex emotion of message sender, it is difficult to distinguish between Function (7) and the other functions. It is too difficult to distinguish whether the positive feeling is motivated by the content or just occurring parallel in typing message, so Function (7) is ignored in this research (Li \& Yang, 2018). Through observing data collected, the author found that there are some emojis emerging alone. Therefore, two other functions were cited from others' research: turn-taking and backchannel device (Ikeda \& Bysouth, 2013). So, the seven pragmatic functions of emoji in this paper are: (1) attitudelemotion signal (F1), (2) attitudelemotion enhancer (F2), (3) illocutionary modifier (F3), (4) joking (F4), (5) irony (F5), (6) turn-taking and (F6), and (7) backchannel device (F7).

In China, people from seven years old to 17 years old are juvenile. People from 18 years old to 40 years old are youth. People from 41 years old to 60 years old are middle-aged. People aged above 60 are old people. Since juvenile and old people have low frequency in using mobile phone, this study only takes youth and middle-aged people into consideration.

\section{Data Collection}

All data collected are from the real communication environment in WeChat group. And all messages collected as research material are permitted by users. There are many factors that could affect the use of emoji, such as gender, age, interlocutors' relationship, and personal competence (Rezabek \& Cochenour, 1998). To control extraneous variables, this study collected chat transcripts from two WeChat groups in May 1 to May 30, one is group (Group 1) with four young females whose relationship is friend, and the other group (Group 2) is five middle-aged females whose relationship is also friend. The author collected totally 1,683 messages in Group 1 (including typed message, dynamic pictures, voice message, and emoji) and 1,410 messages in Group 
2 (also including typed message, dynamic pictures, voice message, and emoji). And all data were analyzed by SPSS.

\section{Research Objects}

Since the launch of WeChat in 2011, acquiescent emoji (called stickers in WeChat) have been revised many times. In January 2021, WeChat is up to the vision of 8.0.3 and there are 109 emoji, which include traditional yellow face; hands; food and other categories. According to research by Provine, Spender and Mandell (2007), smile and laugh are the most frequent used emoji in CMC. So, this paper takes "smile" emoji as research objects. So, the following is seven types of "smile" emoji:

Table 2

Seven Types of "Smile" Emoji

\begin{tabular}{|c|c|c|c|c|c|c|c|}
\hline Emoji & •? & $\hat{3}$ & (6) & (6) & 80 & 6 & $\Leftrightarrow$ \\
\hline English name & Smiley & Grin & Chuckle & Laugh & Tick & Smirk & $\mathrm{LOL}$ \\
\hline Chinese name & 微笑 & 呲牙笑 & 偷笑 & 慜笑 & 坏笑 & 奸笑 & 破涕为笑 \\
\hline
\end{tabular}

\section{Data Analysis and Results}

Among 1,683 messages, 396 emojis exist in Group 1, including 184 other types of emoji and 212 "smile" emojis and the frequency of each "smile" emoji is presented in Table 1. Among 1,410 messages, 239 emojis exist in Group 2, including 107 other types of emoji and 132 "smile" emojis and the frequency of each "smile" emoji is presented in Table 2. If emojis are used twice or more in the same place in message, they are considered as occurring one time, because in real communication message senders usually use repeated emoji to strengthen the meaning conveyed by emoji.

Table 3

Frequency of "Smile" Emoji Among Middle-Aged People

\begin{tabular}{lllllll}
\hline & Laugh & Chuckle & Grin & Tick & Smiley & Total \\
\hline Number & 71 & 26 & 105 & 6 & 4 & 212 \\
Frequency (\%) & 33.49 & 12.26 & 49.54 & 2.82 & 1.89 & 100 \\
\hline
\end{tabular}

Table 4

Frequency of "Smile" Emoji Among Youth

\begin{tabular}{llllllll}
\hline & Chuckle & Grin & Tick & Smiley & Lol & Smirk & Total \\
\hline Number & 15 & 13 & 17 & 8 & 74 & 5 & 132 \\
Frequency (\%) & 11.36 & 9.85 & 12.88 & 6.06 & 56.06 & 3.79 & 100 \\
\hline
\end{tabular}

The result shows both middle-aged people and youth are more likely to use "smile" emoji than other types of emoji (53.53\% in Group 1 and 55.23\% in Group 2), which is coincident with the research from other scholars (Rezabek \& Cochenour, 1998). There are differences in using "smile" emoji between youth and middle-aged people. From Tables 1 and 2, it is "grin" emoji that uses the most frequent (49.54\%) in Group 1, while in Group 2, "lol" emojis are mostly used (56.06\%). However, there is no existence of "lol" emoji in Group 1, and the use frequency of the "grin" emoji in Group 2 is much lower $(9.85 \%)$. It is also noticeable that "smiley" emoji in both groups hold the lowest use frequency (1.89\% in Group 1 and $6.06 \%$ in Group 2). 


\section{Similar Frequency but Different Function "Smiley" Emoji}

Although the distribution of "smiley" emoji is similar between the two groups, there was a big difference between the two groups in understanding what it meant.

In Groups 1 and 2, "smiley" emojis play Function 1 (emotional lattitude signal) most. But through analyzing the conversation among research objects, the result found that Function 1 between two groups is different, in that Group 1 is more likely to use it to express positive attitudelemotion while Group 2 is more likely to use it to express negative attitudelemotion.

e.g., (1) from Group 1

\begin{tabular}{|c|c|c|c|c|}
\hline 1 & \begin{tabular}{|l|}
$09,05,2021$ \\
$7: 56: 32$
\end{tabular} & $A$ & 今天是母亲节 $\cdot ?$ & Today'is"Mother': •- \\
\hline 2 & $09,05,2021$ & A & 小宇（A 的女儿）给我发红包了 & My'daughter'send'me'a'Hongbao. \\
\hline
\end{tabular}

According to Yus (2014), in face-to-face communication and video call, interlocutors could be derived from vision (e.g., facial expression, gesture, body language, and so on) and sound (e.g., intonation of utterance and exclamatory sound uttered by humans such as, sigh, cheer, and so on). However, both vision and sound system would not achieve in communication on keyboard, and for this reason, emoticons play the attitude signal role. So, in this conversation, Speaker A received a hongbao from her daughter, which means benediction and care. And Speaker A, as a mother, must be delighted. However, the sentence "Today is Mother's Day" is feelingless, so the addition of "smiley" emoji indicated that Speaker A wanted to express a positive emotion to other members in this chat group.

e.g., (2) from Group 2

\begin{tabular}{|l|l|l|l|l}
\hline 1 & $\begin{array}{l}02,05,2021 \\
11: 25: 32\end{array}$ & A & 外面下雨了 $\odot$ & It's`raining`now $\odot$ \\
\hline 2 & $\begin{array}{l}02,05,2021 \\
11: 25: 43\end{array}$ & A & 然而我没带伞 & But॰・have`no'umbrella \\
\hline
\end{tabular}

Obviously, in this example, raining could arouse both positive and negative feeling, but the Message 2 indicated that Speaker A did not want to rain because she did not take an umbrella. So, by using the "smiley" emoji in Message 1, Speaker A wanted to express a sad emotion to other members in this chat group.

After comparing all "smiley" emoji in both groups, we can conclude that middle-aged people tend to use "smiley" emoji as a positive meaning, while youth tend to use it as a negative meaning, which is opposite to the literal meaning of "smiley" emoji.

\section{Different Frequency but Similar Function—“Grin” Emoji}

The use frequency between Group 1 (49.54\%) and Group 2 (9.85\%) is extremely different, but the function of this emoji appears similar. This emoji in WeChat communication is used to signal positive emotion or to enhance positive emotion. The similarity between Group 1 and Group 2 in using this emoji is that "grin" emoji is used to strengthen illocutionary force.

e.g., (3) from Group 1 


\begin{tabular}{|c|c|c|c|c|}
\hline $1 \leftarrow$ & $12,05,2021$ & $A$ & 明天出去玩都穿啥啊 & $\begin{array}{l}\text { What will you wear tomorrow to go } \\
\text { playing? }\end{array}$ \\
\hline 2 & $12,05,2021$ & $\mathrm{~B}$ & 不知道啊 & I don't know \\
\hline 3 & $12,05,2021$ & $\mathrm{C}$ & @A 你把衣服都带着 $\hat{\Theta} \hat{\Theta}$ & @A Take all of your clothes $\hat{\hat{\Theta}}$ \\
\hline
\end{tabular}

Emotions may also relate or soften the illocutionary force of speech acts and thus communicating a more adequate extent of the impact that the user intends with his her words (Dresner \& Herring, 2010). In this example, the five people in this chat group were going to excursion. They were discussing the clothes to take. A said that she had cats and clothes. Then, $\mathrm{C}$ asked $\mathrm{A}$ to take all her clothes to excursion. This message without the "grin" emoji is an order which would be very rude to A and would hurt the face of A. However, the "grin" emoji indicates that the message should not be taken as a request or demand. With this emoji, the illocutionary meaning of order will be softened to save face for both interlocutors.

So, observing all "grin" emojis in both groups, the result shows "grin" emojis play a similar function among youth and middle-aged people which is to strengthen $\backslash$ mitigate illocutionary force in most cases; however, specifically, this emoji also was more likely to be used to soften illocutionary force and to avoid face threatening.

\section{Emoji Exist Only in One Group but Similar Function—“Laugh" Emoji and "Lol" Emoji}

It is unique that "laugh" emoji did not occur in the conversation record in Group 2, because the "laugh" emoji is more official than other smiles. And there is no occurrence of "lol" emoji in Group 1, because this emoji was introduced in the latest version of WeChat and many middle-aged people are not familiar with it.

"Laugh" emoji, as the second frequent used emoji among middle-aged people, could play all the seven pragmatic functions of emoticons. And another reason why youth did like to use this emoji is that the meaning of this emoji is too complex to identify and is easy to misunderstand. The most occurred function is a attitudelemotional signal.

e.g., (4) from Group 1

\begin{tabular}{|l|l|l|l|l}
\hline 1 & $\begin{array}{l}05,05,2021 \\
18: 16: 34\end{array}$ & A & 大家都干啥呢 & What is everybody doing? \\
\hline 2 & $\begin{array}{l}20,05,2021 \\
18: 17: 02\end{array}$ & B & $\begin{array}{l}\text { 我去共和(中国北部的一个小城市 } \\
\text { 了 }\end{array}$ & $\begin{array}{l}\text { I have come to GongHe (a small city } \\
\text { in North China) already }\end{array}$ \\
\hline
\end{tabular}

"I have come to X town" is a sentence which has no explicit attitude or emotion, but B added the "laugh" emoji to imply positive emotion. So, in this case, the "laugh" emoji serves as an attitudelemotional signal function.

"Lol" emoji, as the second frequent used emoji among youth, could play all the seven pragmatic functions of emoticons. The top three most used functions of "lol" emoji are illocutionary modifier, attitude signal and attitude enhancer.

e.g., (5) from Group 2 


\begin{tabular}{|l|l|l|l|l}
\hline 1 & $\begin{array}{l}19,05,2021 \\
8: 03: 33\end{array}$ & A & 今天天气可真是太好了 & It is a sunny day today \\
\hline 2 & $\begin{array}{l}19,05,2021 \\
8: 03: 40\end{array}$ & A & 太阳大的我都不想出去 & Sun is too big to go out. \\
\hline
\end{tabular}

When communicating online, speakers also expected to embed the propositional form of their message in a particular attitude under which the utterance is typed (Yus, 2014). In this conversation, A said that the weather is good, seemingly, it will express a positive feeling but by adding the "lol" emoji, receiver of this massage will understand that A means that the positive thing is negative to her. So, in this respect, this emoji is not only an attitude enhancer but also an attitude changer.

Although "laugh" emoji and "lol" emoji both occur only in Groups 1 and 2, they serve as the same pragmatic function in Chinese WeChat communication.

\section{Similar in Both Use Frequency and Function-"Tick", "Smirk" and "Chuckle" Emoji}

These emojis appeared semblable regulations in Groups 1 and 2. Over sixty percent of "chuckle" emoji play the joking function in both groups. And about "tick" and "smirk" emoji, the most frequent used function is joking in both groups.

e.g., (6) from Group 2

\begin{tabular}{|l|l|l|l|l|}
\hline 1 & $\begin{array}{l}20,05,2021 \\
9: 13: 12\end{array}$ & A & 我穿这个约会好看吧 & $\begin{array}{l}\text { Is' it' beautiful' and' suitable' for } \\
\text { dating? }\end{array}$ \\
\hline 2 & $\begin{array}{l}20,05,2021 \\
9: 13: 15\end{array}$ & B & $\begin{array}{l}\text { 穿这个出去约会, 不会半路被色 } \\
\text { 狼劫走了吧 }\end{array}$ & $\begin{array}{l}\text { If' you' wear' this' cloth, you' may' be } \\
\text { robbed' by' a'lady-killer' on' the' road } \\
\text { to'dating.+ }\end{array}$ \\
\hline
\end{tabular}

Yus (2014) indicated that emoji can be used to a signal that the utterance should not be interpreted literally. However, the connotative meaning is to joke about some affairs. Thus, the attitude is not that of endorsement but of humorous. In this example, this conversation happened on 20 May, which is a day for lovers because "520" is homophobic with "I love you" in Chinese. On that day, A had a date with her boyfriend and tried the new clothes. She took a photo of the cloth, sent it to the chat group and expected it to be affirmed by other members. Obviously, A's picture was not complimented but denied by B due to the potential danger, but B added a "chuckle" emoji to make it clear that she was being humorous and she did not want B to interpret this sentence in literal meaning.

The finding shows that there is no significant difference in using "chuckle", "tick", and "smirk" emoji between people of different ages.

\section{Conclusion}

Through comparing the use frequency and pragmatic function of emoji between people of different ages, this study found that there are four categories of "smile" emojis in Chinese WeChat communication among people of different ages. The first is that the use frequency is similar but the function is different, which is "smiley" emoji. The meaning of this emoji is totally opposite among youth and middle-aged people. So, when communicators communicate with people who are not their own age group, they should avoid using "smile" emoji to reduce misunderstanding. The second is that the use frequency is different but the function is similar, 
which is "grin" emoji. According to this research, people of middle age are more likely to use this emoji than youth. So, in order to achieve successful communication, youth could use more "grin" emoji to establish a close relationship with them. The third category is that emojis exist only in one group, "laugh" which is only among middle-aged people and "lol" which is only among youth. The last category includes emoji are similar in both use frequency and function, which are "chuckle", "tick", and "smirk".

Moreover, this research found among 109 emojis, "facepalm" emoji takes a huge percentage between two groups of people. So, in future study, research about "facepalm" will be significant.

\section{Limitation}

Although this research is significant, there are some limitations in this paper. The first limitation is that corpus size is smaller than a standard corpus. So, representation is weak. The second is that some irrelevant variables are out of control, for example, educated level of interlocutors, region of interlocutors, religion of interlocutors, and so on. The third is that wordsmith is not able to identify emoji, so all the types of emojis and functions were classified by hand. Therefore, in further study, researchers could set up a more large-scale corpus, and take more influence factors into consideration.

\section{References}

Crystal, D. (2001). Language and the internet. Cambridge: Cambridge University Press.

Darics, E. (2012). Instant message in work-based virtual teams: The analysis of non-verbal communication used for the contextualization of transactional and relational communicative goals. Retrieved from http://erika.darics.co/download/darics_phd.pdf

Diane, F. Witmer \& Sandra Lee Katzman. (1997). On-line smiles: Does gender make a difference in the use of graphic accents? Journal of Computer-Mediated Communication, 2(4), 1083-6101.

Dresner, E., \& Herring, C. (2010). Functions of the nonverbal in CMC: Emoticons and illocutionary force. Communication Theory, 20(3), 1468-2885.

Ge, J., \& Herring, S. C. (2018). Communicative functions of emoji sequences on Sina Weibo. First Monday, 23(11). Retrieved from https://doi.org/10.5210/fm.v23i11.9413

Gibson, W., Huang, P. P., \& Yu, Q. Y. (2018). Emoji and communicative action: The semiotics, sequence and gestural actions of "face covering hand". Discourse, Context \& Media, 26, 91-99.

Glenn, P. (2003). Laughter in interaction. Cambridge: Cambridge University Press.

Halliday, M. A. K. (1978). Language as social semiotic: The social interpretation of language and meaning. London: Edward Arnold.

Holt, E. (2013). Conversation analysis and laughter. In C. A. Chapelle (Ed.), The encyclopedic of applied linguistics (pp. 1033-1038). Chichester: Blackwell.

Ikeda, K., \& Bysouth, D. (2013). Laughter and turn-taking: Warranting next speakership in multiparty interaction. In P. Glenn and E. Holt (Eds.), Studies in laughter in interaction (pp. 39-64). London: Bloomsbury Publishing.

Kavanagh, B. (2010). A cross-cultural analysis of Japanese and Chinese non-verbal online blogging communities. Language \& Communication, 48, 53-65.

Li, L., \& Yang, Y. (2018). Pragmatic functions of emoji in internet-based communication-a corpus-based study. Asian-Pacific Journal of Second and Foreign Language Education, 3(16). Retrieved from https://sfleducation.springeropen.com/articles/10.1186/s40862-018-0057-z

Luor, T., Wu, L. L., Lu, H. P., \& Tao, Y. H. (2010). The effect of emoticons in simplex and complex task-oriented communication: An empirical study of instant messaging. Computers in Human Behavior, 26(5), 889-895.

McKay, I. (2020). Some distributional patterns in the use of typed laughter-derived expressions on Twitter. Journal of Pragmatics, 166(4), 97-113.

Provine, R. R., Spencer, R. J., \& Mandell, D. L. (2007). Emotional expression online Emoticons punctuate website text messages. Language Social Psychol, 26(3), 299-307. 
Rezabek, L. L., \& Cochenour, J. J. (1998). Visual cues inn computer-mediated communication: Supplementing text with emoticons. Journal of Visual Literacy, 18(2), 201-215.

Sampietro, A. (2019). Emoji and rapport management in Spanish WhatsApp chats. Journal of Pragmatics, 143(4), 109-120. doi:10.1016/j.pragma.2019.02.009

Tossell, C. C., Kortum, P., Shepard, C., \& Barg-Walkow, L. H. (2012). A longitudinal study of emoticon uses in text messaging from smartphones. Computers in Human Behavior, 28(2), 659-663.

Yus, F. (2014). Not all emoticons are created equal. Linguagemem (Dis)curso, 14(3). Retrieved from https://doi.org/10.1590/1982-4017-140304-0414 